\title{
ERRATUM
}

\section{How words anchor categorization: conceptual flexibility with labeled and unlabeled - ERRATUM}

\author{
JACKSON TOLINS \\ Department of Psychology, University of California, Santa Cruz
}

AND

\section{ELIANA COLUNGA}

Department of Psychology and Neuroscience, University of Colorado, Boulder

doi: http://dx.doi.org/10.1017/langcog.2014.26, Published by Cambridge University Press 22 July 2014.

In the published article Tolins \& Colunga (2012) the last word of the title was omitted and should have read as follows:

How words anchor categorization: conceptual flexibility with labeled and unlabeled categories

The press apologises unreservedly to Jackson Tolins, Eliana Colunga and the readers for this error.

\section{R E F E R E N C E}

Tolins, J., \& Colunga, E. (2014). How words anchor categorization: conceptual flexibility with labeled and unlabeled. Language and Cognition, Available on CJO 2014 doi: http://dx.doi. org/10.1017/langcog.2014.26 